\title{
Psoriasis pathophysiology: current concepts of pathogenesis
}

\author{
J G Krueger, A Bowcock
}

Ann Rheum Dis 2005;64(Suppl II):ii30-ii36. doi: 10.1136/ard.2004.031120

\begin{abstract}
Psoriasis vulgaris is a common skin disorder characterised by focal formation of inflamed, raised plaques that constantly shed scales derived from excessive growth of skin epithelial cells. The disease is defined by a series of linked cellular changes in the skin: hyperplasia of epidermal keratinocytes, vascular hyperplasia and ectasia, and infiltration of $\mathrm{T}$ lymphocytes, neutrophils, and other types of leucocyte in affected skin. In a relatively short period, psoriasis vulgaris has been conceptualised as a T lymphocyte mediated autoimmune disease and new biological therapies that target $\mathrm{T}$ cells have just entered routine clinical practice. Similarly, rapid progress has been made towards dissecting cellular and molecular pathways of inflammation that contribute to disease pathogenesis. This short review presents current pathogenic concepts that have emerged from genetic, genomic, and cellular information obtained in basic studies and from clinical studies of selective immune targeting drugs.
\end{abstract}

$\mathrm{T}$ oday, psoriasis vulgaris is recognised as the most prevalent autoimmune disease caused by inappropriate activation of the cellular immune system. Psoriasis affects people of all ages, but there is a strong tendency for disease onset in early adulthood in patients who develop psoriasis due to genetic transmission. ${ }^{1}$ There has been a major international effort to characterise psoriasis susceptibility genes, but until recently, virtually nothing learned from linkage analysis has advanced the understanding of disease pathophysiology. Unlike other common tissue specific autoimmune diseases, psoriasis vulgaris does not have a generally accepted animal model, and thus our understanding of pathogenesis is derived mainly from clinical studies and translational science done in patients with this disease. That work initially pointed towards a major role of T lymphocytes as inducers of the disease phenotype and the pathogenic contribution of this cell type has now been tested through clinical studies of more than a dozen immune modifying biological agents in patients with psoriasis. The success of translational research in psoriasis is probably best illustrated by the US Food and Drug Administration's (FDA's) approval of alefacept and efalizumab in 2003. Alefacept is a fusion protein that binds to CD2 on T cells, and efalizumab is a humanised antibody that binds to leucocyte function associated antigen-1 (LFA-1), an integrin expressed at high levels on $\mathrm{T}$ cells. $^{23}$ However, as work in psoriasis has advanced, we have also learned that inflammatory cytokines such as tumour necrosis factor (TNF) are likely to play major pathogenic roles in this disease $\mathrm{e}^{4}$ and that other types of inflammatory leucocytes may also serve key pathogenic functions. Rather than viewing psoriasis as a disease caused by a single cell type or a single inflammatory cytokine, it is probably best to conceptualise disease pathogenesis as linked to many interactive responses between infiltrating leucocytes, resident skin cells, and an array of proinflammatory cytokines, chemokines, and chemical mediators produced in the skin under regulation of the cellular immune system. Here we will review some recent work on psoriasis that advances our overall understanding of disease pathophysiology as impacted by genetic, genomic, and immune contributions.

\section{GENETIC BASIS OF PSORIASIS}

Psoriasis and associated psoriatic arthritis (PsA) are complex genetic diseases with environmental and genetic components. Approximately $10-30 \%$ of patients with psoriasis develop PsA. This suggests that susceptibility factors for psoriasis are also susceptibility factors for PsA. However, the development of PsA in psoriasis patients may require additional environmental stimuli or additional genetic factors that predispose to inflammation of the joints as well as the skin. Interestingly, in psoriasis, arthritis, and autoimmune arthritis in mice, self-reactive $\mathrm{T}$ cells do not destroy synoviocytes but stimulate them to proliferate. This may be due a genetic predisposition leading to a high sensitivity of synoviocytes or keratinocytes in patients to various activating stimuli. Other variants may result in inflammatory cells with a lower threshold for activation or a prolonged state of activation. This hypothesis is supported by the examples provided below where variants associated with the development of arthritis or psoriasis are frequently associated with the immune system.

In recent years, genetic analyses of multiply affected families or cases have identified some susceptibility variants for psoriasis and PsA. Genome-wide linkage scans suggest many additional susceptibility loci for which genes still need to be identified. One of the most compelling susceptibility factors for psoriasis is the presence of human leucocyte antigen (HLA)-Cw*0602 (discussed elsewhere in this issue by Rahman and Elder ${ }^{5}$ ) which was found in $\sim 10 \%$ of healthy northern European controls and $\sim 50 \%$ of psoriasis patients but in $<20 \%$ of patients with PsA. ${ }^{6}$

Other susceptibility loci for psoriasis reside on chromosomes 1q21, 3q21, 4q, 7p, 8, 11, 16q, 17q, and 20p, and many others have been proposed following genome-wide linkage scans of primarily nuclear families with two affected individuals. ${ }^{6}$ Recently, two regions on chromosome $17 \mathrm{q}$ were precisely localised with association mapping. ${ }^{7}$ These regions are separated by $\sim 6 \mathrm{Mb}$ so that their contribution to psoriasis susceptibility appears to be independent. The two genes within the first peak are SLC9A3Rl and NAT9. The gene within the second peak is RAPTOR.

SLC9A3R1 is a scaffold protein linking plasma membrane proteins to the actin cytoskeleton in polarised epithelial cells. $^{8-10}$ It is via SLC9A3Rl that external signals to plasma

\footnotetext{
Abbreviations: CLA, cutaneous lymphocyte antigen; iDC, immature dendritic cell; IFN, interferon; IL, interleukin; LFA-1, leucocyte function associated antigen-1; mDC, mature dendritic cell; $M H C$, major histocompatibility complex; NF $\kappa B$, nuclear factor $\kappa B$; NK-T, natural killer $\mathrm{T}$ (cells); $\mathrm{PDC}$, plasmacytoid dendritic cell; $\mathrm{PsA}$, psoriatic arthritis; RA, rheumatoid arthritis; STAT, signal transducer and activator of transcription; TNF, tumour necrosis factor; TCR, T cell receptor; TOR, target of rapamycin
} 
membrane proteins lead to alterations in signal transduction and cell growth. In the T cell, SLC9A3RI lies within the lipid raft and may be involved in formation of the immune synapse. ${ }^{11}$ Dysregulation of this gene could delay the formation of the synapse, increasing the time that antigen is presented to the T cell receptor, hence leading to prolonged inflammation. Interestingly, a solute carrier mapping to chromosome 3q21, SLC12A8, has been shown to be associated with psoriasis in Swedish families. ${ }^{12}$

The predisposing variant near SLC9A3Rl and NAT9 is likely to be loss of a RUNX1 site lying within the $1.2 \mathrm{~kb}$ region $3^{\prime}$ of both of the genes. ${ }^{7}$ This variant is relatively common in the population; hence, its effect upon psoriasis susceptibility is relatively low. This reinforces the prevailing belief that psoriasis susceptibility variants, like most variants predisposing to complex disease, are common in the population and have weak effects, requiring the presence of additional susceptibility factors. RUNXI is a transcription factor exerting a major role on the development of cells of haematopoietic origin. It may be acting within the bone marrow, thymus, or the periphery. It is possible that it also acts within the synovium or keratinocytes of the skin, altering their response to an immune signal. ${ }^{67}$

The consequence of loss of this RUNXl site is unknown. However, alterations in RUNXl sites in other genes predispose to other autoimmune diseases. In both cases these sites lie within introns. One lies within an intron of the PD-1 (PDCD1) gene and predisposes to systemic lupus erythematosus. ${ }^{13}$ The PD-1 gene codes for an immunoreceptor that is a member of the Ig superfamily harbouring an immunoreceptor tyrosine based inhibitory motif. Interaction of PD-1 with its ligand leads to inhibition of anti-CD3 induced $\mathrm{T}$ cell activation by reducing interleukin (IL)-2 production and inhibition of proliferation and cytokine production.

The other RUNXI variant lies within an intron of SLC22A4 on chromosome $5 \mathrm{q} 31$ and predisposes to rheumatoid arthritis (RA). ${ }^{13}{ }^{14}$ SLC22A4 is specific to haematological and immunological tissues and is induced by proinflammatory stimuli. It is highly expressed in the inflammatory joints of mice with collagen induced arthritis, and it is proposed that it may function as a transporter in lymphoid organs or an inflammatory milieu. ${ }^{14}$ The RA associated variant leads to RUNXl binding and it is proposed that its excessive expression contributes to development of RA.

RAPTOR lies in the region of psoriasis linkage on chromosome 17q25 that was first detected in a large multiply affected family with psoriasis. ${ }^{14}{ }^{15}$ Some of the affected members in this family also developed PsA at an early age. Hence it is tempting to speculate that a regulatory variant in RAPTOR predisposes to both psoriasis and PsA. RAPTOR binds to and regulates the function of mTOR (target of rapamycin), a key regulator of $\mathrm{T}$ cell function and growth. mTOR is a component of a cytokine triggered protein kinase cascade leading to the phosphorylation of the eukaryotic initiation factor (eIF)-4E binding protein, PHAS-1, in activated $\mathrm{T}$ lymphocytes. This event promotes Gl phase progression by stimulating eIF-4E dependent translation initiation. ${ }^{15}{ }^{16}$ Rapamycin binds to and blocks the function of mTOR, leading to immunosuppression.

Two genome-wide scans have identified additional regions that may predispose to PsA susceptibility. One is located on chromosome 16q and overlaps with the location of a psoriasis locus. ${ }^{17}$ The other is located on chromosome 15q. ${ }^{18}$ Recent studies on a cohort of PsA patients from Newfoundland suggest that variants within CARD15 on chromosome $16 \mathrm{q}$ predispose to $\mathrm{PsA}^{18}$ since they were found in $28 \%$ of patients versus $12 \%$ of controls. CARD15 is proposed to activate nuclear factor $\kappa \mathrm{B}(\mathrm{NF \kappa B})$ in response to bacterial lipopolysaccharides. ${ }^{19}$
Variants within several other genes have been shown to predispose to arthritis in mice. For example, a variant of the neutrophil cytosolic factor 1 ( Ncfl) leads to rat arthritis. ${ }^{20}$ The protein encoded by this gene regulates the oxidative burst of neutrophils, and the disease related allele promotes the activation of arthritogenic T cells in lymphoid organs, rather than in peripheral inflammatory joints through an oxygen burst response. Chronic autoimmune arthritis in mice is due to a mutation in the SH2 domain of ZAP70, a key signal transduction molecule in $\mathrm{T}$ cells that is expressed early in haematopoietic development. ${ }^{21}$ It is proposed that this mutation changes the thresholds of $\mathrm{T}$ cells to thymic selection, leading to the positive selection of otherwise negatively selected autoimmune $\mathrm{T}$ cells. While mapping the ZAP70 gene, a second linkage peak was mapped to the murine major histocompatibility complex (MHC) region. This linkage was observed only when mice were maintained in a nearly specific pathogen free condition and homozygosity of the H-2d haplotype conferred high genetic susceptibility to arthritis.

Hence psoriasis and arthritis of many types are due to both susceptibility variants of the MHC as well as variants that alter $\mathrm{T}$ cell responses during development, during thymic selection, or in the periphery.

\section{CELLULAR BASIS OF PSORIASIS}

Although psoriasis vulgaris is usually identified by the clinical appearance of characteristic red, raised, scaly skin lesions, it is best defined as a unique skin disease by a set of underlying cellular changes (histopathology). Clinical features, then, are explained by impressive growth and dilation of superficial blood vessels (redness) and equally impressive hyperplasia of the epidermis. Epidermal growth occurs in a pattern termed "psoriasiform" hyperplasia, which describes both elongated rete pegs, thickening (acanthosis), and differentiation changes. In psoriatic epidermis, keratinocytes proliferate and mature rapidly so that terminal differentiation, normally occurring in granular keratinocytes and then squamous corneocytes, is incomplete. Hence, squamous keratinocytes aberrantly retain intact nuclei (parakeratosis) and release few extracellular lipids that normally cement adhesions of corneocytes. Accordingly, poorly adherent stratum corneum is formed and this results in the characteristic scale or flakes of psoriasis lesions. Psoriasis vulgaris is a disease of the interfollicular epidermis, and it does not significantly alter the growth of follicular epithelia or the normal hair growth cycle. Rarely, a few small pustules can be identified in very inflamed psoriasis plaques, but usually leucocyte infiltration in psoriasis plaques is a microscopic finding. The appearance of mononuclear leucocytes in the papillary dermis and polymorphonuclear leucocytes (neutrophils) in the stratum corneum are defining features of psoriasis histopathology. However, even with this characteristic array of cellular changes, it is necessary to exclude skin infection by yeast or fungi, since the immune reaction to these microbes can produce a virtually identical histological picture.

As will become apparent from the discussion below, most current models of disease pathogenesis are focused on actions or secreted cytokines of activated leucocytes that, in turn, produce reactive changes in skin cells according to preprogrammed pathways. Hence, let us review the array of leucocyte subsets that appear in psoriasis vulgaris skin lesions (fig 1). Of course, neutrophils have long been identified in active lesions, since they have characteristic nuclei and cytoplasmic staining properties. However, as mononuclear leucocytes have come to be studied in psoriasis, particularly with antibody based methods, it has become clear that neutrophils are actually quite variably expressed in 


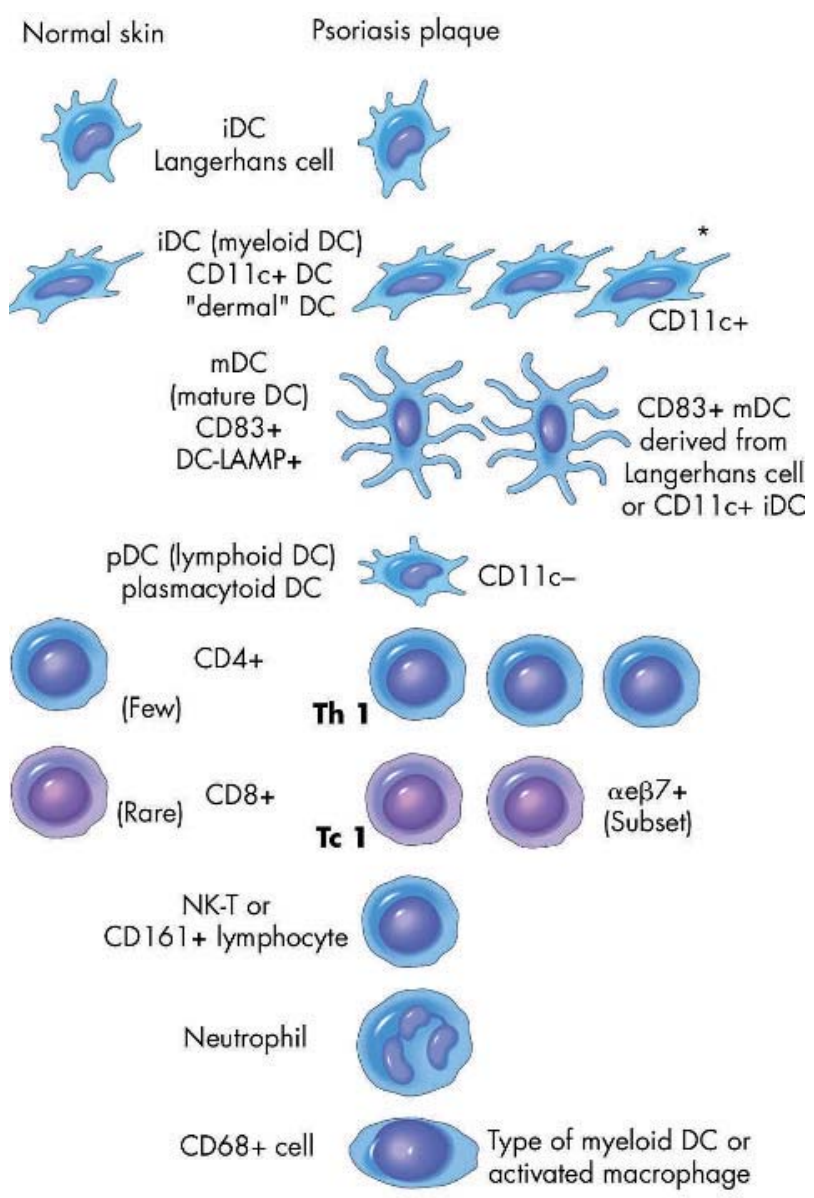

Figure 1 The array of leucocyte subsets that appear in psoriasis vulgaris lesions. iDC, immature dendritic cell; NK-T, natural killer T (cells).

psoriasis lesions from different patients. In contrast, increased numbers of $\mathrm{T}$ lymphocytes are a highly consistent finding in psoriasis biopsies. With immunohistochemical staining, $\mathrm{T}$ lymphocytes are found interspersed between keratinocytes throughout the epidermis and in somewhat larger quantities in the dermis. ${ }^{22-24}$ In fact, a significant fraction of dermal "mononuclear" inflammatory cells seen in routine sections is due to $\mathrm{T}$ cell infiltration. $\mathrm{T}$ cell subsets are not uniformly distributed in psoriasis lesions. Epidermal $\mathrm{T}$ cells are chiefly CD8+ T cells, with a significant fraction of these cells specialised for homing to epithelia through expression of the integrin $\alpha e \beta 7$, which binds E-cadherin associated with desmosomes. ${ }^{25}{ }^{26}$ Dermal T lymphocytes are a mixture of CD4+ and CD8+ cells, with a CD4+ predominance similar to that seen in peripheral blood. Natural killer (NK)-T cells may well be present in psoriasis lesions based on staining with NK surface markers, ${ }^{25}{ }^{26}$ but further work is needed to confirm their identity. Overall, the magnitude of $\mathrm{T}$ cell infiltration in skin lesions is quite impressive. For example, we calculate that a patient with $20 \%$ body surface affected with psoriasis lesions has about eight billion $\mathrm{T}$ cells circulating in blood, but $\sim 20$ billion $\mathrm{T}$ cells located in dermis and epidermis of psoriasis plaques. Most $\mathrm{T}$ cells in skin lesions are memory cells that express cutaneous lymphocyte antigen (CLA), the skin addressin. ${ }^{27}$ In contrast, only $\sim 10 \%$ of circulating $\mathrm{T}$ lymphocytes are CLA+. Hence, CLA+ T cells are impressively and selectively targeted to inflammatory psoriasis lesions.
Dendritic cells form another major class of leucocytes that is found in increased abundance in psoriatic skin lesions. Here we will try to consider dendritic cell subsets in psoriasis according to current, but constantly evolving, classifications. ${ }^{28}$ Langerhans cells, considered as one type of immature dendritic cell (iDC), are resident in normal epidermis and also can be found in psoriasis lesions, sometimes in increased abundance. ${ }^{29}$ Dermal DCs, identified initially by strong expression of MHC II or factor XIIIa, can be considered another type of iDC that is similar to interstitial/myeloid iDCs widely distributed in other tissues. ${ }^{30}$ It is likely that iDCs derive from blood monocytes or other myeloid precursors and that these cells can be further stimulated to become mature DCs (mDCs), cells that have potent immunostimulatory capacity for T lymphocytes. Psoriasis lesions show a marked increase in dermal DCs, whether marked by XIIIa expression, CDllc expression (one of the most consistent markers of myeloid DCs), or mannose receptor. ${ }^{31}{ }^{32}$ A very similar DC subset, termed inflammatory epidermal dendritic cell (IDEC), is increased in the epidermis of active lesions, as determined by multiparameter flow cytometry. ${ }^{32}$ The best marker of $\mathrm{mDC}$ is expression of CD83 and DC-LAMP proteins, and many CD83+ and DC-LAMP+ mDCs are present in epidermis and dermis of psoriasis lesions based on immunophenotyping. In contrast, few CD83+ or DC-LAMP+ mDCs are found in normal skin, uninvolved skin of psoriasis patients, or resolved psoriasis lesions based on comparable methods ${ }^{34}$ (and F Chamian et al, submitted for publication). Since $\mathrm{mDC}$ are potent stimulators of $\mathrm{T}$ cells, these observations fit neatly with earlier work (done before markers to identify iDC $v$ mDC populations were available) which showed that DCs from psoriasis lesions were able to activate T cells, whereas those from uninvolved or normal skin did not have stimulatory activity. ${ }^{35}$ Finally, another type of DC termed plasmacytoid DC (pDC) is dramatically increased in psoriatic skin. ${ }^{36}$ Although pDCs are a minor DC subset in skin lesions, they have the ability, if activated, to produce extremely large amounts of interferon $\alpha$ (IFN $\alpha$ ). In contrast, activated/mature myeloid DCs are known to be major producers of IL-12 and IL-23 and thus strong polarisers of T cell responses. ${ }^{37}{ }^{38}$ Given that pDCs enter peripheral tissues exclusively from blood stores and that most CDllc+ (myeloid) DCs also originate from blood precursors, the overall infiltration of psoriasis lesions by DC subsets is highly impressive. In rough terms, the number of DCs present in psoriasis lesions equals or exceeds the number of $\mathrm{T}$ cells, even though fewer $\mathrm{DC}$ precursors are normally contained in the blood. In the pathogenic models discussed below, we discuss how DCs, T cells, and their cytokine products are likely to interact to produce pathogenic inflammation in psoriasis lesions.

\section{DEFINING THE PSORIASIS “TRANSCRIPTOME"}

Much as psoriasis has been defined previously by histopathology, it is now possible to provide a new disease definition based on functional genomics or analysis of expressed genes. Genomic analysis builds on cellular information, since some expressed genes will serve to identify new cell populations in skin tissue and others will relate to changes in activation or differentiation of cells. Most recently, altered expression of $>1300$ genes in lesional versus uninvolved skin was identified using 63000 element gene arrays. $^{38}$ These data provide some unique insights into regulation of inflammation in psoriatic tissue. Firstly, the array of chemokines expressed in skin lesions is much larger than previously recognised, with elevated expression of at least 16 distinct ligands. Unexpectedly, chemokines that have expression normally restricted to lymph nodes and formal lymphoid tissues are elevated in psoriasis. Two of these (secondary lymphoid chemokine/CCL21, MIP3//CCL19) bind 


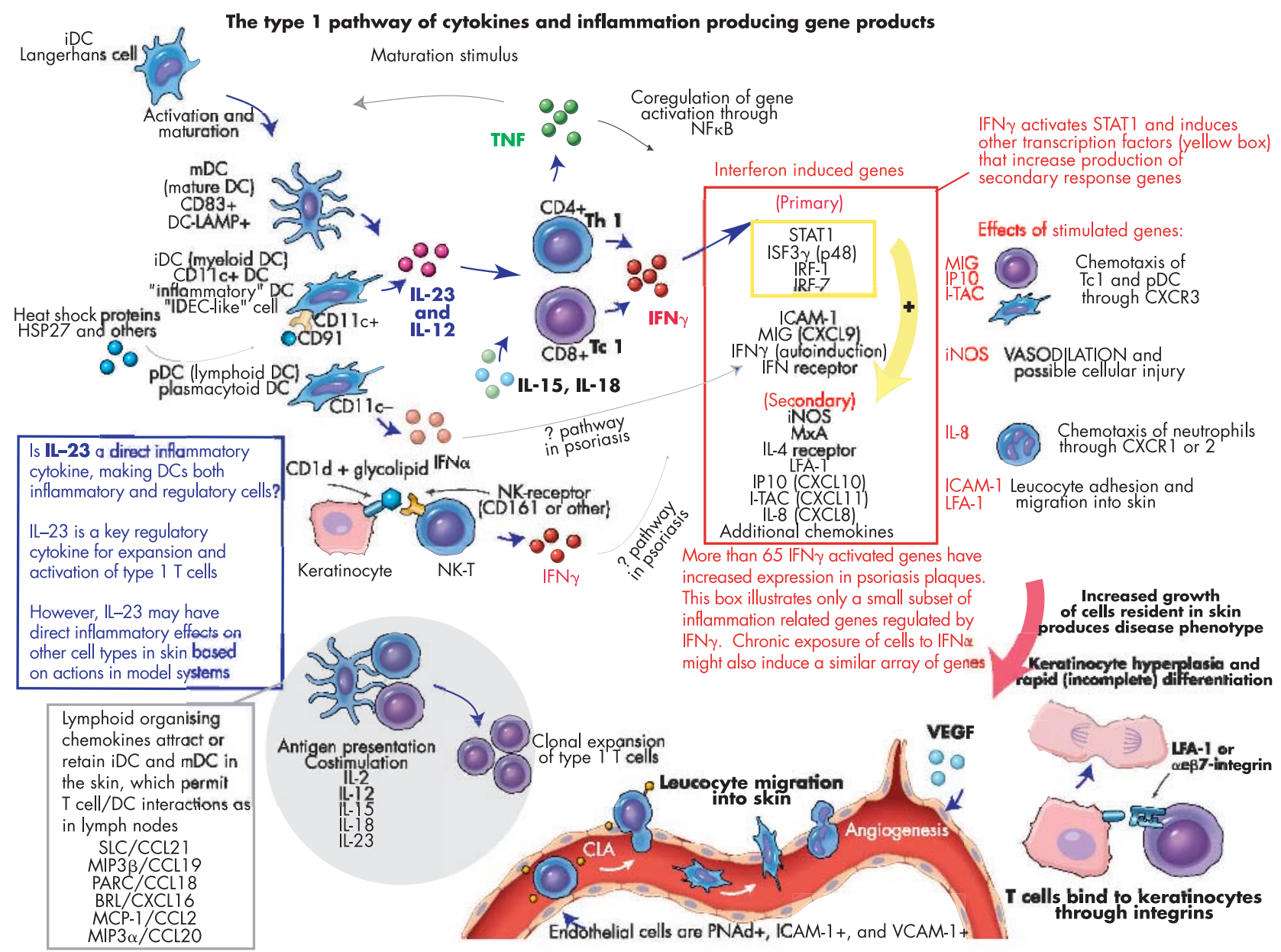

Figure 2 Alternative pathways of leucocyte activation that converge to activate type 1 inflammatory genes which, in turn, regulate end stage inflammation in skin and the appearance of the psoriasis phenotype. BRL, Bonzo receptor ligand; DC, dendritic cell; ICAM, intercellular adhesion molecule; ITAC, interferon inducible T cell $\alpha$ chemoattractant; IL, interleukin; IFN, interferon; iNOS, inducible nitric oxide synthase; IP10, interferon inducible protein 10; IRF, interferon regulatory factor; ISF, interferon stimulated factor; LFA-1, leucocyte function associated antigen-1; MCP, monocyte chemoattractant protein; MIG, monokine induced by interferon $\gamma ; M I P$, macrophage inflammatory protein; MxA, interferon induced cellular resistance mediator protein; NF, nuclear factor; NK, natural killer (cell); PARC, pulmonary and activation regulated chemokine; PNAd, peripheral node addressin; TNF tumour necrosis factor; SLC, secondary lymphoid tissue chemokine; STAT, signal transducer and activator of transcription; VCAM, vascular cell adhesion molecule; VEGF, vascular endothelial growth factor.

to CCR7, a chemokine receptor that marks lymph node homing $\mathrm{T}$ cells, but this receptor was also unexpectedly detected on $\mathrm{T}$ cells in psoriasis lesions. Importantly, ectopic expression of this group of chemokines in peripheral tissues has been shown in model systems to be a sufficient stimulus to organise $\mathrm{DC}$ and $\mathrm{T}$ cell infiltrates and to produce autoimmune tissue destruction. Hence, in situ expression of lymphoid organising chemokines in psoriasis might explain not only the impressive array of DCs in diseased skin but $\mathrm{T}$ cell activation and chronic disease activity. Secondly, the genomic analysis has identified increased expression of many other immune regulating and proinflammatory gene products. Many of these inflammatory genes can be explained by activation of a type $\mathrm{l}$ pathway in which $\mathrm{T}$ helper $\mathrm{l} / \mathrm{T}$ cytotoxic 1 (Th $1 /$ Tc 1 ) T cells release IFN $\gamma$ upon activation. Secreted IFN $\gamma$ subsequently activates signal transducer and activator of transcription l (STATl) which then increases transcription of a large group of immune related genes. Increased expression of $>65$ genes, or $\sim 5 \%$ of the psoriasis transcriptome, can be explained by this IFN $\gamma$ activated pathway. Importantly, key cellular features of psoriasis can be explained through induction of IFN regulated genes. For example, induction of nitric oxide synthase (iNOS) produces the potent vasodilator nitric oxide; the induction of the chemokines MIG, I-TAC, and IP10 can explain the accumulation of CXCR3+CD8+ T cells in lesions; and induction of IL-8 provides a strong chemotactic signal for ongoing neutrophil recruitment (fig 2). Genomic analysis by real time reverse transcriptase polymerase chain reaction (RT-PCR) (which is inherently more sensitive than array based methods) has also identified increased expression IL-23, of a key inducer of IFN $\gamma$ synthesis and type $1 \mathrm{~T}$ cell polarity. ${ }^{39}$ Given that CDIlc+ and CD83+ DCs appear to be the major cellular sources of IL23 in psoriasis lesions, these data provide yet another link between accumulation of activated/mature DCs in skin regions and the subsequent activation of the type 1 pathway. Potentially, pDC could contribute to the array of IFN induced genes, as chronic exposure of cells to IFN $\alpha$ will activate most of these genes. ${ }^{40}$ Activated NK-T cells might also be another cellular source of IFN $\gamma .{ }^{26}$ 


\section{DISSECTING PATHOGENIC IMMUNE PATHWAYS IN THE CLINIC}

The response of psoriasis to $\mathrm{T}$ lymphocyte targeted biological agents, which are inherently more specific antagonists than conventional drugs, provides a good deal of the evidence that these cells are key pathogenic contributors in psoriasis vulgaris. Resolution of skin disease has been induced by agents that target activated T cells or T cell costimulation, and by administration of cytokines that decrease type $1 \mathrm{~T}$ cell activation (reviewed in reference 23). Two $\mathrm{T}$ cell targeted biologicals, alefacept and efalizumab, recently received approval by the FDA for psoriasis vulgaris. Alefacept is an LFA3Ig fusion protein that binds to $\mathrm{CD} 2$, a molecule expressed mainly on $\mathrm{T}$ cells. Alefacept selectively depletes memory $\mathrm{T}$ cells in psoriasis skin lesions and thus reduces expression of type 1 inflammatory gene products in diseased skin. Efalizumab is a humanised antibody that binds to CDlla, the defining subunit of LFA-1. LFA-l is strongly downregulated on $\mathrm{T}$ cells after efalizumab binding, and the outcome of this interaction leads to reduced numbers of $\mathrm{T}$ cells in skin lesions and to marked reductions in mRNAs for type 1 inflammatory genes in skin lesions. Here we should acknowledge that large scale clinical trials of alefacept ${ }^{2}$ and efalizumab $^{41}$ have clearly established that a significant fraction (perhaps half of treated patients) does not have a major clinical response after three months of treatment. The reason for response heterogeneity is not known but possibilities include variable expression of redundant immune controlling pathways in different patients or variable contributions of $\mathrm{T}$ lymphocytes to the overall inflammatory reaction. With this in mind, marked improvements in psoriasis produced by the TNF antagonists infliximab $^{42}$ and etanercept ${ }^{43}$ have come as somewhat of a surprise, particularly if one views TNF's actions as centred mainly in innate immune responses. Although mechanistic actions of TNF inhibitors in psoriasis are presently unknown, we note that a number of inflammatory type 1 genes can be coregulated by IFN $\gamma$ and TNF through composite promoters that bind STATl and NFKB ${ }^{44}$ and that TNF is known to be an effector (bactericidal) cytokine induced in tissue macrophages by $\mathrm{T}$ cells through IFN $\gamma$ release. In addition, TNF is a key cytokine for inducing the activation of iDC to become $\mathrm{CD} 83+\mathrm{mDC}^{45}$ so TNF could theoretically stimulate in situ activation/maturation of DCs in psoriasis lesions.

Although we have gained key insights into the pathogenesis of psoriasis by doing clinical studies with selective immune agonists or antagonists, the rapid pace of clinical trials has largely outstripped basic and translational research into effects of these agents on normal and pathological immunity. There is tremendous opportunity in the future to learn about cellular and molecular mechanisms of autoimmune inflammation by studying actions of specific agents in concert with powerful new genomic and cellular approaches. Without doubt, targeted drugs will continue to allow testing of mechanistic hypotheses of inflammation, such as testing of the extent to which newly discovered molecules like IL-23 or secondary lymphoid chemokine (CCL21) regulate pathogenic immunity in humans.

\section{SOME NEW INFORMATION FROM EXPERIMENTAL MODELS}

Transgenic animals have provided a good deal of information about in vivo cellular activation that can be achieved by excessive production of specific inflammatory molecules in the skin. Interesting studies were reported recently about two sets of transgenic mice. ${ }^{46-48}$ Previously, a mouse was constructed with transgenic overexpression of the IL-12 p40 subunit. ${ }^{46}$ Curiously, marked skin inflammation occurred even though a functional IL-12 molecule (p35/p40 dimer) was not produced. However, at that time IL-23 had not yet been discovered, but today we know the (IL-12) p40 subunit can combine with a unique p19 subunit to form IL-23 (p19/ p40 dimer). Re-examination of the p40 transgenic showed excessive formation of IL-23 in the skin due to endogenous upregulated synthesis of the p19 subunit. The overall inflammatory phenotype includes marked increases in DCs and $\mathrm{T}$ cells along with impressive epidermal hyperplasia. ${ }^{47}$ Although the histological picture in mouse skin is not psoriasis, parallels in cellular activation with psoriasis vulgaris are striking, especially considering impressive upregulation of IL-23 in psoriatic lesions. Another very interesting study reported on the effects of transgenic overexpression of vascular endothelial growth factor (VEGF) in the skin. ${ }^{48}$ The resulting phenotype is a blend of vascular hyperplasia, increased $\mathrm{T}$ cell infiltration, and epidermal hyperplasia in mouse skin that shares some striking parallels with psoriasis. There are also effects on follicular epithelium and hair growth that are not part of psoriasis vulgaris, but overall this study shows that a vascular growth factor can trigger unexpected immune infiltrates and that there may be some additional mechanism to coordinate growth of superficial cutaneous blood vessels and epidermal keratinocytes.

Xenotransplantation models (human skin grafted to immunodeficient mice) have also provided key insights into psoriasis pathophysiology. Two recent studies are noteworthy. One report has shown that an antibody to IL-15, which could inhibit both $\mathrm{T}$ cell proliferation and TNF release from monocytes in vitro, had a remarkable ability to reverse histological features of psoriasis lesions grafted on severe combined immunodeficiency (SCID) mice. ${ }^{49}$ Potentially, IL15 serves as a master regulatory cytokine in psoriasis with the ability to induce downstream cytokines including TNF, IFN $\gamma$, and IL-17, and with the ability to regulate expansion/ differentiation of CD8+ T cells and NK cells in particular. It will be extremely interesting to test IL-15 antagonists in clinical studies. A novel psoriasis model is the subject of another recent report. ${ }^{50}$ Nestle and coworkers have grafted uninvolved (pre-psoriatic) skin of psoriasis patients to AGR129 mice which lack both IFN receptors and a recombinase (RAG2). With the highly immunosuppressed background of this mouse strain, human $\mathrm{T}$ cells that were carried in the original skin graft can expand and will produce a spontaneous psoriasis lesion. The lesion can be prevented by treating engrafted skin with CD3 antibodies (blocking $\mathrm{T}$ cell expansion) or TNF inhibitors. Though not fully explored, DCs appear to expand and activate along with $\mathrm{T}$ cells in the environment of human skin. This model is important because it is the first to permit spontaneous disease appearance under conditions where $\mathrm{T}$ cells activate/expand under the influence of endogenous antigens, cytokines, and other regulatory mechanisms. The model suggests that human skin (perhaps as influenced by fundamental genetic alterations in psoriasis) can serve not only as a long term reservoir of pathogenic immune cells, but also frank growth and expansion of skin homing memory $\mathrm{T}$ cells can occur exclusively within the skin. Hence, the skin can potentially function as a surrogate of formal lymphoid tissue, at least for expansion of already differentiated skin homing $\mathrm{T}$ cells.

\section{INTEGRATING INFORMATION INTO PATHOGENIC MODELS}

Figure 2 shows a number of alternative pathways of leucocyte activation that converge to activate type 1 inflammatory genes and which, in turn, regulate end stage inflammation in skin and the appearance of the psoriasis phenotype. We consider that both activated DCs and "proximal" cytokines such as IL-12, IL-15, IL-18, and IL-23 could contribute to 
type 1 T cell activation, expansion, and polarisation. However, at this point, it is not entirely certain whether pathogenic inflammation results from classical activation of $\mathrm{T}$ cells (mediated by a peptide antigen through the $\mathrm{T}$ cell receptor (TCR)) or whether NK-T cells may be activated by nonclassical antigens such as glycolipids. ${ }^{51}$ Under some circumstances, mixtures of proinflammatory cytokines can trigger IFN $\gamma$ release from $\mathrm{T}$ cells independent of TCR engagement, ${ }^{52}$ and these pathways might also be operative in psoriasis. Activation of DCs may be caused by cell exposure to inflammatory cytokines, heat shock proteins, CD40L induced on activated T cells, antigen capture, or in response increased synthesis of an array of lymphoid organising chemokines in focal skin regions (see box in fig 2). The result of $\mathrm{T}$ cell (or NK-T cell) activation is release of IFN $\gamma$, the defining cytokine of type $1 \mathrm{~T}$ cells, and also TNF, which is co-produced by activated type $1 \mathrm{~T}$ cells. In turn, IFN $\gamma$ becomes a key middle cytokine that activates STATl and a series of other transcription factors that produce end molecules of inflammation, such as iNOS, chemokines, and adhesion molecules that stimulate inward trafficking of many types of leucocyte. Activation of this pathway might also be stimulated by chronic release of IFN $\alpha$ from pDCs, if they become activated in the skin. Frank inflammation (redness/oedema), vascular hyperplasia, and $\mathrm{T}$ cell binding to keratinocytes result from activation of type 1 genes. The epidermal growth/differentiation programme in psoriasis is largely regenerative hyperplasia, a type of hyperplasia programmed in keratinocytes as an injury-repair response pathway. The immune trigger may relate to direct damage to keratinocytes produced by leucocyte trafficking in the epidermis and/or a response to inflammation related cytokines.

Still, we have much to learn about how psoriasis susceptibility genes contribute to the overall pathogenic process. We hypothesise that genetic alterations could well affect the extent to which immune cells or keratinocytes activate to a given stimulus (PSORS2) and/or affect primary antigen presentation (PSORS1, if actually related to the HLACw6 locus). We also face the issue of understanding how differing pathways of T cells and DC activation contribute to inflammation in the psoriasis lesion and how this relates to response heterogeneity to targeted immune therapeutics. In the end, we must use the sum of information available to construct testable hypotheses of pathogenesis that may lead us directly to specific and safe therapeutic agents. The information developed in psoriasis can help not only patients with this disease, but also might be applied more broadly to other autoimmune diseases that seem to share cellular and molecular mechanisms of pathogenic inflammation.

\section{Authors' affiliations \\ J G Krueger, Laboratory for Investigative Dermatology, Rockefeller University, New York, USA}

A Bowcock, Department of Genetics, Washington University School of Medicine, St. Louis, MO, USA

Correspondence to: J Krueger, Rockefeller University, 1230 York Ave, New York, NY 10021 USA; igk@rockefeller.edu

\section{REFERENCES}

1 Lebwohl M. Psoriasis. Lancet 2003;361:1197-204

2 Krueger GG, Callis KP. Development and use of alefacept to treat psoriasis. J Am Acad Dermatol 2003;49:S87-S97.

3 Gordon KB, Papp KA, Hamilton TK, Walicke PA, Dummer W, Li N, Bresnahan BW, et al. Efalizumab Study Group. Efalizumab for patients with moderate to severe plaque psoriasis: a randomized controlled trial. JAMA 2003;290:3073-80

4 Victor FC, Gottlieb AB. TNF-alpha and apoptosis: implications for the pathogenesis and treatment of psoriasis. J Drugs Dermatol 2002;1:264-75.

5 Rahman P, Elder JT. Genetic epidemiology of psoriasis and psoriatic arthritis. Ann Rheum Dis 2005;64(suppl II):ii37-9.
6 Bowcock AM, Cookson WO. The genetics of psoriasis, psoriatic arthritis and atopic dermatitis. Hum Mol Genet 2004; 13:R43-R55

7 Helms C, Cao L, Krueger JG, Wijsman EM, Chamian F, Gordon D, et al. A putative RUNX1 binding site variant between SLC9A3R1 and NAT9 is associated with susceptibility to psoriasis. Nat Genet 2003;35:349-56.

8 Shenolikar S, Weinman EJ. NHERF: targeting and trafficking membrane proteins. Am J Physiol Renal Physiol 2001;280:F389-F395.

9 Voltz JW, Weinman EJ, Shenolikar S. Expanding the role of NHERF, a PDZdomain containing protein adapter, to growth regulation. Oncogene 2001;20:6309-14.

10 Weinman EJ. New functions for the NHERF family of proteins. J Clin Invest 2001;108:185-6.

11 Itoh K, Sakakibara M, Yamasaki S, Takeuchi A, Arase H, Miyazaki M, et al. Cutting edge: negative regulation of immune synapse formation by anchoring lipid raft to cytoskeleton through Cbp-EBP50-ERM assembly. J Immunol 2002;168:541-4

12 Hewett D, Samuelsson L, Polding J, Enlund F, Smart D, Cantone K, et al. Identification of a psoriasis susceptibility candidate gene by linkage disequilibrium mapping with a localized single nucleotide polymorphism map. Genomics 2002;79:305-14.

13 Prokunina L, Castillejo-Lopez C, Oberg F, Gunnarsson I, Berg L, Magnusson $\mathrm{V}$, et al. A regulatory polymorphism in PDCDI is associated with susceptibility to systemic lupus erythematosus in humans. Nat Genet 2002;32:666-9.

14 Tokuhiro S, Yamada R, Chang X, Suzuki A, Kochi Y, Sawada T, et al. An intronic SNP in a RUNX1 binding site of SLC22A4, encoding an organic cation transporter, is associated with rheumatoid arthritis. Nat Genet 2003;35:341-8.

15 Tomfohrde J, Silverman A, Barnes R, Fernandez-Vina MA, Young M, Lory D, et al. Gene for familial psoriasis susceptibility mapped to the distal end of human chromosome 17q. Science 1994;264:1141-5.

16 Brunn GJ, Williams J, Sabers C, Wiederrecht G, Lawrence JC Jr, Abraham RT. Direct inhibition of the signaling functions of the mammalian target of rapamycin by the phosphoinositide 3-kinase inhibitors, wortmannin and LY294002. EMBO J 1996;15:5256-67.

17 Karason A, Gudjonsson JE, Upmanyu R, Antonsdottir AA, Hauksson VB, Runasdottir $\mathrm{EH}$, et al. A susceptibility gene for psoriatic arthritis maps to chromosome 16q: evidence for imprinting. Am J Hum Genet 2003;72:125-31.

18 Samuelsson L, Enlund F, Torinsson A, Yhr M, Inerot A, Enerback C, et al. A genome-wide search for genes predisposing to familial psoriasis by using a stratification approach. Hum Genet 1999;105:523-9.

19 Rahman P, Bartlett S, Siannis F, Pellett FJ, Farewell VT, Peddle L, et al. CARD 15: a pleiotropic autoimmune gene that confers susceptibility to psoriatic arthritis. Am J Hum Genet 2003;73:677-81.

20 Olofsson P, Holmberg J, Tordsson J, Lu S, Akerstrom B, Holmdahl R. Positional identification of $\mathrm{Ncfl}$ as a gene that regulates arthritis severity in rats. Nat Genet 2003;33:25-32.

21 Sakaguchi N, Takahashi T, Hata H, Nomura T, Tagami T, Yamazaki S, et al. Altered thymic T-cell selection due to a mutation of the ZAP-70 gene causes autoimmune arthritis in mice. Nature 2003;426:454-60.

22 Gottlieb SL, Gilleaudeau P, Johnson R, Estes L, Woodworth TG, Gottlieb AB, et al. Response of psoriasis to a lymphocyte-selective toxin (DAB389IL-2) suggests a primary immune, but not keratinocyte, pathogenic basis. Nat Med 1995; 1:442-7.

23 Krueger JG. The immunologic basis for the treatment of psoriasis with new biologic agents. J Am Acad Dermatol 2002;46:1-23.

24 Rottman JB, Smith TL, Ganley KG, Kikuchi T, Krueger JG. Potential role of the chemokine receptors CXCR3, CCR4, and the integrin alphaEbeta7 in the pathogenesis of psoriasis vulgaris. Lab Invest 2001;81:335-47.

25 Ferenczi K, Burack L, Pope M, Krueger JG, Austin LM. CD69, HLA-DR and the IL-2R identify persistently activated T cells in psoriasis vulgaris lesional skin: blood and skin comparisons by flow cytometry. J Autoimmun 2000; 14:63-78.

26 Bonish B, Jullien D, Dutronc Y, Huang BB, Modlin R, Spada FM, et al. Overexpression of CDId by keratinocytes in psoriasis and CDId-dependent IFN-gamma production by NK-T cells. J Immunol 2000;165:4076-85.

27 Fuhlbrigge RC, Kieffer JD, Armerding D, Kupper TS. Cutaneous lymphocyte antigen is a specialized form of PSGL-1 expressed on skin-homing T cells. Nature 1997;389:978-81.

28 Shortman K, Liu YJ. Mouse and human dendritic cell subtypes. Nat Rev Immunol 2002;2:151-61.

29 McGregor JM, Barker JN, Ross EL, MacDonald DM. Epidermal dendritic cells in psoriasis possess a phenotype associated with antigen presentation: in situ expression of beta 2-integrins. J Am Acad Dermatol 1992;27:383-8.

30 Nestle FO, Zheng XG, Thompson CB, Turka LA, Nickoloff BJ. Characterization of dermal dendritic cells obtained from normal human skin reveals phenotypic and functionally distinctive subsets. J Immunol 1993;151:6535-45.

31 Deguchi M, Aiba S, Ohtani H, Nagura H, Tagami H. Comparison of the distribution and numbers of antigen-presenting cells among T-lymphocytemediated dermatoses: CDla+, factor Xllla+, and CD68+ cells in eczematous dermatitis, psoriasis, lichen planus and graft-versus-host disease. Arch Dermatol Res 2002;294:297-302.

32 Wollenberg A, Kraft S, Hanau D, Bieber T. Immunomorphological and ultrastructural characterization of Langerhans cells and a novel, inflammatory dendritic epidermal cell (IDEC) population in lesional skin of atopic eczema. J Invest Dermatol 1996;106:446-53.

33 Abrams JR, Kelley SL, Hayes E, Kikuchi T, Brown MJ, Kang S, et al. Blockade of T lymphocyte costimulation with cytotoxic T lymphocyte-associated antigen 4-immunoglobulin (CTLA4lg) reverses the cellular pathology of psoriatic 
plaques, including the activation of keratinocytes, dendritic cells, and endothelial cells. J Exp Med 2000;192:681-94.

34 Koga T, Duan H, Urabe K, Furue M. In situ localization of CD83-positive dendritic cells in psoriatic lesions. Dermatology 2002;204:100-3.

35 Nestle FO, Turka LA, Nickoloff BJ. Characterization of dermal dendritic cells in psoriasis. Autostimulation of T lymphocytes and induction of Th1 type cytokines. J Clin Invest 1994;94:202-9.

36 Wollenberg A, Wagner M, Gunther S, Towarowski A, Tuma E, Moderer M, et al. Plasmacytoid dendritic cells: a new cutaneous dendritic cell subset with distinct role in inflammatory skin diseases. J Invest Dermatol 2002;119:1096-102.

37 Oppmann B, Lesley R, Blom B, Timans JC, Xu Y, Hunte B, et al. Novel p19 protein engages IL-12p40 to form a cytokine, IL-23, with biological activities similar as well as distinct from IL-12. Immunity 2000;13:715-25.

38 Zhou X, Krueger JG, Kao MC, Lee E, Du F, Menter A, Wong WH, et al. Novel mechanisms of T-cell and dendritic cell activation revealed by profiling of psoriasis on the 63,100-element oligonucleotide array. Physiol Genomics 2003; 13:69-78.

39 Lee E, Trepicchio WL, Oestreicher JL, Pittman D, Wang F, Chamian F, et al. Increased expression of interleukin $23 \mathrm{p} 19$ and p40 in lesional skin of patients with psoriasis vulgaris. J Exp Med 2004;199:125-30.

40 Boehm U, Klamp T, Groot M, Howard JC. Cellular responses to interferongamma. Annu Rev Immunol 1997:15:749-95.

41 Lebwohl M, Tyring SK, Hamilton TK, Toth D, Glazer S, Tawfik NH, et al. A novel targeted T-cell modulator, efalizumab, for plaque psoriasis. NEngl J Med 2003;349:2004-13

42 Gottlieb AB, Chaudhari U, Mulcahy LD, Li S, Dooley LT, Baker DG. Infliximab monotherapy provides rapid and sustained benefit for plaque-type psoriasis. J Am Acad Dermatol 2003;48:829-35.

43 Leonardi CL, Powers JL, Matheson RT, Goffe BS, Zitnik R, Wang A, et al; Etanercept Psoriasis Study Group. Etanercept as monotherapy in patients with psoriasis. N Engl J Med 2003;349:2014-22.
44 Pine R. Convergence of TNFalpha and IFN gamma signalling pathways through synergistic induction of IRF-1/ISGF-2 is mediated by a composite GAS/kappaB promoter element. Nucleic Acids Res 1997;25:4346-54.

45 Buchler T, Hajek R, Bourkova L, Kovarova L, Musilova R, Bulikova A, et al. Generation of antigen-loaded dendritic cells in a serum-free medium using different cytokine combinations. Vaccine 2003;21:877-82

46 Kopp T, Kieffer JD, Rot A, Strommer S, Stingl G, Kupper TS. Inflammatory skin disease in K14/p40 transgenic mice: evidence for interleukin-12-like activities of p40. J Invest Dermatol 2001;117:618-26.

47 Kopp T, Lenz P, Bello-Fernandez C, Kastelein RA, Kupper TS, Stingl G. IL-23 production by cosecretion of endogenous $\mathrm{p} 19$ and transgenic $\mathrm{p} 40$ in keratin 14/p40 transgenic mice: evidence for enhanced cutaneous immunity. $\mathrm{J}$ Immunol 2003;170:5438-44

48 Xia YP, Li B, Hylton D, Detmar M, Yancopoulos GD, Rudge JS. Transgenic delivery of VEGF to mouse skin leads to an inflammatory condition resembling human psoriasis. Blood 2003;102:161-8.

49 Villadsen LS, Schuurman J, Beurskens F, Dam TN, Dagnaes-Hansen F, Skov L, et al. Resolution of psoriasis upon blockade of IL-15 biological activity in a xenograft mouse model. J Clin Invest 2003;112:1571-80.

50 Boyman O, Hefti HP, Conrad C, Nickoloff BJ, Suter M, Nestle FO. Spontaneous development of psoriasis in a new animal model shows an essential role for resident T cells and tumor necrosis factor-alpha. J Exp Med 2004; 199:731-6.

51 Curry JL, Qin JZ, Bonish B, Carrick R, Bacon P, Panella J, et al. Innate immunerelated receptors in normal and psoriatic skin. Arch Pathol Lab Med 2003;127:178-86

52 Tominaga K, Yoshimoto T, Torigoe K, Kurimoto M, Matsui K, Hada T, et al. IL12 synergizes with IL-18 or IL-1 beta for IFN-gamma production from human $T$ cells. Int Immunol 2000;12:151-16. 